\title{
Combined treatment of diabetic nephropathy with alprostadil and calcium dobesilate
}

\author{
LILI QIN ${ }^{1}$, WENJUN QIN ${ }^{2}$, JIANFEI WANG ${ }^{3}$ and LIN LIN $^{1}$ \\ ${ }^{1}$ Department of Nephrology, Weifang People's Hospital, Weifang, Shandong 261041; \\ ${ }^{2}$ Department of Urology, Hanting People's Hospital of Weifang, Weifang, Shandong 261100; \\ ${ }^{3}$ Department of Radiology, Weifang People's Hospital, Weifang, Shandong 261041, P.R. China
}

Received May 29, 2017; Accepted September 6, 2017

DOI: $10.3892 / \mathrm{etm} .2017 .5115$

\begin{abstract}
This study investigated the effects of alprostadil combined with calcium dobesilate on the treatment of diabetic nephropathy. We recruited 80 patients with diabetic nephropathy, who were randomly divided into experimental $(\mathrm{n}=40)$ and control $(n=40)$ groups. Patients received high-quality lowprotein diabetic diet intervention and subcutaneous injection of insulin to adjust blood glucose, combined with antihypertensive, antiplatelet drugs, and other comprehensive treatments. The control group received alprostadil and the experimental group received alprostadil combined with calcium dobesilate. Both groups were treated for 12 weeks as one treatment cycle. The time to remission of clinical symptoms such as mental fatigue and weakness, limb edema, soreness and swelling of waist and knee, cold limbs and limb numbness and pain was significantly shorter in the experimental group than that in the control group $(\mathrm{p}<0.05)$. After intervention, the blood levels of small molecular weight proteins, such as $\beta 2$-microglobulin ( $\beta 2-\mathrm{MG})$, cystatin $\mathrm{C}(\mathrm{Cys} C)$, and retinol binding protein (RBP), were significantly lower in the experimental group than those in the control group $(p<0.05)$. The levels of the inflammatory cytokines tumor necrosis factor- $\alpha$ (TNF- $\alpha$ ), interleukin-6 (IL-6), and $\mathrm{C}$-reactive protein (CRP) were significantly lower in the experimental group than those in the control group $(\mathrm{p}<0.05)$. The levels of 25-hydroxyvitamin D and parathyroid hormone were significantly higher in the experimental group than those in the control group $(p<0.05)$. The level of angiotensin II was lower in the experimental group than that in the control group $(p<0.05)$ and the level of fasting serum insulin was significantly higher in the experimental group than that in the control group $(\mathrm{p}<0.05)$. The homeostasis model assessment of insulin resistance (HOMA-IR) index was lower in the experimental group than that in the control group $(\mathrm{p}<0.05)$. The levels of renal function indexes, blood urea nitrogen, creatinine and uric
\end{abstract}

Correspondence to: Dr Lin Lin, Department of Nephrology, Weifang People's Hospital, 151 Guangwen Street, Kuiwen, Weifang, Shandong 261041, P.R. China

E-mail: lin_linwf@163.com

Key words: alprostadil, calcium dobesilate, diabetic nephropathy acid, in experimental group were lower than those in control group $(\mathrm{p}<0.05)$. The levels of brain derived neurotrophic factor (BDNF) and insulin-like growth factor-1 (IGF-1) were significantly higher in both groups after the intervention than those before the intervention $(\mathrm{p}<0.05)$. The levels of BDNF and IGF-1 were higher in the experimental group than that in control group after intervention $(\mathrm{p}<0.05)$. The application of alprostadil combined with calcium dobesilate in patients with diabetic nephropathy can effectively relieve clinical symptoms, improve renal functions, reduce blood levels small proteins, alleviate the inflammatory response, and regulate the levels of BDNF and IGF-1, thus improving the clinical treatment effect.

\section{Introduction}

Diabetic nephropathy is the most common microvascular complication of diabetes and the most common cause of endstage renal failure (1). With the modern changes in dietary structure and life style, the morbidity of diabetes has increased steadily. More than $10 \%$ of people aged over 60 years suffer from type 2 diabetes (2), and $\sim 20 \%$ of diabetic patients develop diabetic nephropathy. Diabetic nephropathy is the second leading cause of death in diabetic patients and deserves special clinical attention (3).

Alprostadil is a drug that can effectively expand renal blood vessels and directly act on glomerular arteries and their smooth muscles after spasms caused by increased blood glucose (4). Thus, alprostadil increases renal blood flow, reduces the renal vascular resistance, and glomerular capillary pressure (5), improving renal blood supply and reducing the level of urine protein (6). Alprostadil also demonstrates activity inhibiting platelet aggregation, anti-oxidation and stabilizing cell membranes. The treatment of diabetic nephropathy has a long history, but a single application of alprostadil fails to delay the pathological changes in renal vascular endothelial cells; hence, alprostadil alone cannot fundamentally prevent diabetic nephropathy. Calcium dobesilate can effectively inhibit the synthesis of transforming growth factor (TGF) and protein kinase $\mathrm{C}$, thereby reducing blood viscosity and vascular wall permeability. Moreover, calcium dobesilate has a protective effect on the vascular endothelium, thus improving renal function (7). In order to improve the clinical outcomes 
Table I. Time to clinical remission after intervention (day, mean \pm SD).

\begin{tabular}{lccccc}
\hline Group & $\begin{array}{c}\text { Mental fatigue } \\
\text { and weakness }\end{array}$ & Limb edema & $\begin{array}{c}\text { Soreness and swelling } \\
\text { of waist and knee }\end{array}$ & Cold limbs & $\begin{array}{c}\text { Limb numbness } \\
\text { and pain }\end{array}$ \\
\hline Experimental & $6.7 \pm 1.1$ & $2.7 \pm 0.3$ & $7.1 \pm 1.3$ & $8.9 \pm 0.8$ & $12.3 \pm 1.5$ \\
Control & $12.4 \pm 1.6$ & $5.5 \pm 0.6$ & $10.3 \pm 1.5$ & $12.3 \pm 1.5$ & $20.1 \pm 1.9$ \\
t-value & 18.567 & 26.399 & 10.196 & 12.649 & 20.379 \\
P-value & $<0.05$ & $<0.05$ & $<0.05$ & $<0.05$ & $<0.05$ \\
\hline
\end{tabular}

and reverse the pathological process in diabetic nephropathy, this study mainly discussed the therapeutic value of alprostadil combined with calcium dobesilate for diabetic nephropathy.

\section{Subjects and methods}

Subject data. We recruited 80 patients with diabetic nephropathy in Weifang People's Hospital from January, 2015 to December, 2016. Patients were comprehensively diagnosed via clinical manifestations and biochemical tests, and they conformed to the diagnostic criteria of diabetic nephropathy of the Chinese Medical Association in 2010. Informed consents were signed by the patients and/or guardians, and the study was approved by the Ethics Committee of Weifang People's Hospital. Patients showing complications with severe cardiopulmonary dysfunction, coagulation disorder, mental disease, infection in other tissues and organs, secondary hypertension, type 1 diabetes, and central nervous system disease were excluded. According to a random number table, the patients were divided into experimental $(n=40)$ and control $(n=40)$ groups. The experimental group included 21 males and 19 females aged $49-75$ years (63.5 \pm 2.7 years on average), with a duration of diabetes of 5-40 years $(23.1 \pm 2.6$ years on average) and a duration of diabetic nephropathy of 2-12 years $(6.1 \pm 1.1$ years on average). The control group contained 21 males and 19 females aged 49-75 years (63.3 \pm 2.6 years on average), with a duration of diabetes of 5-40 years $(23.0 \pm 2.5$ years on average) and a duration of diabetic nephropathy of 2-12 years $(6.0 \pm 1.1$ years on average). There were no significant differences in gender, age, and duration of diabetes and diabetic nephropathy between the two groups ( $\mathrm{p}>0.05)$.

Methods. Patients underwent high-quality low-protein diabetic diet intervention and subcutaneous injection of insulin to adjust blood glucose, combined with antihypertensive and antiplatelet drugs, and other comprehensive treatment. The control group was treated with an intravenous injection of $10 \mu \mathrm{g}$ alprostadil (NMPN H10980024; Tide Pharmaceutical, Beijing, China) with $18 \mathrm{ml}$ normal saline once a day for 14 consecutive days as one treatment. The next treatment was started two weeks later. The experimental group was treated with alprostadil combined with calcium dobesilate capsules (NMPN H20000711; Xi'an Lijun Pharmaceutical, Xi'an, China) 3 times a day (0.25 g/dose) for four consecutive weeks as one treatment. Both groups were treated for 12 consecutive weeks as one treatment cycle.

Experimental indexes. We compared time to remission of the clinical symptom, changes in serum of small molecular protein level, inflammatory cytokine level, and endocrine-related hormone level between the two groups after intervention. We also compared changes in fasting serum insulin (FINS), homeostasis model assessment of insulin resistance (HOMA-IR) index, renal function between the two groups. Finally, we examined the changes in brain derived neurotrophic factor (BDNF) and insulin-like growth factor-1 (IGF-1) levels in both groups before and after intervention.

Evaluation methods. Elbow venous blood was drawn in the early morning and immediately submitted for detection of relevant biochemical indexes. The levels of serum small molecule proteins as $\beta 2$-microglobulin ( $\beta 2-\mathrm{MG})$, cystatin $\mathrm{C}(\mathrm{CysC})$, and retinol binding protein (RBP) were detected via enzyme-linked immunosorbent assay (ELISA). All reagents were provided by Beijing Jingmei Biology (Beijing, China). Tumor necrosis factor- $\alpha$ (TNF- $\alpha$ ) and interleukin-6 (IL-6) were detected via double-antibody single-step sandwich method. C-reactive protein (CRP) was detected via immunoturbidimetric assay. 25-hydroxyvitamin D was detected via unidimensional chromatography. Parathyroid hormone was detected via ELISA. Angiotensin II was detected via reversed-phase high-performance liquid chromatography (RP-HPLC). FINS was detected via Beckman Access DXI 800 chemiluminescent analyzer. HOMA-IR index $=[$ fasting blood glucose $(\mathrm{mmol} / \mathrm{l}) \times \mathrm{FINS}(\mathrm{mU} / \mathrm{l})] / 22.5$. Renal function tests included the determination of blood urea nitrogen (urease - Nessler colordeveloping method), creatinine (chemiluminescence method), and uric acid levels (ELISA). BDNF was detected via ELISA. The normal reference range of IGF-1 in adults is $80-360 \mathrm{ng} / \mathrm{ml}$.

Statistical analysis. SPSS 13.0 (IBM Corp., New York, NY, USA) was used for statistical processing. Measurement data were presented as mean \pm standard deviation (mean \pm SD). T-test was used for the comparison of means between the two groups and Chi-square test was used for the comparison of rates between the two groups. $\mathrm{p}<0.05$ suggested that the difference was statistically significant.

\section{Results}

Time to clinical remission after intervention. To determine the time to clinical remission, we examined the symptoms of mental fatigue and weakness, limb edema, soreness and swelling of waist and knee, cold limbs and limb numbness and pain. The experimental group achieved remission of each symptom faster than the control group and the differences were statistically significant $(\mathrm{p}<0.05)$ (Table I). 
Table II. Levels of small molecular proteins in blood after intervention $(\mu \mathrm{g} / \mathrm{ml}$, mean $\pm \mathrm{SD})$.

\begin{tabular}{lccc}
\hline Group & $\beta 2-\mathrm{MG}$ & CysC & RBP \\
\hline Normal & $1.60-3.0$ & $0.51-1.09$ & $25-70$ \\
Experimental & $2.11 \pm 0.2$ & $0.81 \pm 0.12$ & $25.31 \pm 0.26$ \\
Control & $3.53 \pm 0.31$ & $1.32 \pm 0.23$ & $43.27 \pm 0.39$ \\
t-value & 24.344 & 12.433 & 242.338 \\
P-value & $<0.05$ & $<0.05$ & $<0.05$ \\
\hline
\end{tabular}

$\beta 2-\mathrm{MG}, \beta 2$-microglobulin; CysC, cystatin C; RBP, retinol binding protein.

Table III. Levels of inflammatory cytokines after intervention (mean $\pm \mathrm{SD})$.

\begin{tabular}{lccc}
\hline Group & TNF- $\alpha(\mathrm{ng} / \mathrm{l})$ & $\mathrm{IL}-6(\mathrm{ng} / \mathrm{l})$ & $\mathrm{CRP}(\mathrm{mg} / \mathrm{l})$ \\
\hline Normal & $5-100$ & $56.4-150.3$ & $\leq 10$ \\
Experimental & $105.3 \pm 5.6$ & $79.6 \pm 3.4$ & $6.3 \pm 0.1$ \\
Control group & $258.1 \pm 11.5$ & $125.3 \pm 5.1$ & $11.3 \pm 1.6$ \\
t-value & 75.552 & 47.155 & 19.726 \\
P-value & $<0.05$ & $<0.05$ & $<0.05$ \\
\hline
\end{tabular}

TNF- $\alpha$, tumor necrosis factor- $\alpha$; IL-6, interleukin-6; CRP, C-reactive protein.

Small molecular weight proteins in blood after intervention. After intervention, we analyzed renal function by measuring the levels of small molecular proteins in blood, including 32-MG, CysC and RBP. The experimental group showed levels within the normal levels for $\beta 2-\mathrm{MG}, \mathrm{Cys} C$ and $\mathrm{RBP}$, but the control group still showed elevated levels of $\beta 2-\mathrm{MG}$ and CysC (Table II). Comparing the values of the proteins for the two groups, the experimental group exhibited lower levels for all three proteins compared to those in the control group. The differences were statistically significant $(\mathrm{p}<0.05)$ (Table II).

Levels of inflammatory cytokines after intervention. After intervention, we examined the levels of the inflammatory cytokines TNF- $\alpha$, IL- 6 and CRP to determine recovery from the nephropathy. The experimental group showed slightly high levels of TNF- $\alpha$ and normal levels of IL- 6 and CRP (Table III). In contrast, the control groups showed normal levels of CRP and elevated levels of TNF- $\alpha$ and IL-6. Comparing the levels of cytokines in the two groups indicated that they were all lower in the experimental groups compared to the control group. The differences were statistically significant $(\mathrm{p}<0.05)$ (Table III).

Levels of endocrine hormones after intervention. After intervention, we examined the levels of 25-hydroxyvitamin D, parathyroid hormone, and angiotensin II. The experimental group showed normal levels of 25-hydroxyvitamin D, low levels of parathyroid hormone, and high levels of angio-
Table IV. Levels of endocrine-related hormones after intervention (mean $\pm \mathrm{SD})$.

\begin{tabular}{lccc}
\hline Group & $\begin{array}{c}\text { 25-hydroxy- } \\
\text { vitamin D } \\
(\mathrm{nmol} / \mathrm{l})\end{array}$ & $\begin{array}{c}\text { Parathyroid } \\
\text { hormone } \\
(\mathrm{ng} / \mathrm{l})\end{array}$ & $\begin{array}{c}\text { Angiotensin II } \\
(\mathrm{ng} / \mathrm{l})\end{array}$ \\
\hline Normal & $\geq 50$ & $170-400$ & $10-30$ \\
Experimental & $65.33 \pm 3.21$ & $158.61 \pm 13.63$ & $36.58 \pm 1.70$ \\
Control & $41.19 \pm 2.10$ & $85.36 \pm 9.54$ & $45.23 \pm 2.91$ \\
t-value & 39.802 & 27.846 & 16.233 \\
P-value & $<0.05$ & $<0.05$ & $<0.05$ \\
\hline
\end{tabular}

Table V. FINS and HOMA-IR indexes after intervention (mean $\pm \mathrm{SD})$.

\begin{tabular}{lcc}
\hline Group & FINS (mU/1) & HOMA-IR \\
\hline Normal & $3.0-24.9$ & 1 \\
Experimental & $4.26 \pm 1.20$ & $0.85 \pm 0.17$ \\
Control & $8.35 \pm 1.61$ & $1.88 \pm 0.91$ \\
t-value & 12.882 & 7.037 \\
P-value & $<0.05$ & $<0.05$ \\
\hline
\end{tabular}

FINS, fasting serum insulin; HOMA-IR, homeostasis model assessment of insulin resistance.

tensin II (Table IV). The control group exhibited low levels of of 25-hydroxyvitamin D and parathyroid hormone, and very high levels of angiotensin II. The differences were statistically significant $(\mathrm{p}<0.05)$ (Table IV).

FINS and HOMA-IR indexes after intervention. FINS was within normal range in both experimental and control groups (Table V). But FINS was significantly higher in the experimental group than that in the control group. The HOMA-IR index in experimental group was lower than that in control group (Table V).

Renal functions after intervention. Next, we examined renal function indexes by analyzing blood urea nitrogen, creatinine and uric acid. The levels of urea nitrogen, creatinine, and uric acid in blood were elevated in both the experimental and control groups. However, the levels were lower in the experimental groups than those in control group. The differences were statistically significant $(\mathrm{p}<0.05)$ (Table VI).

Levels of growth factors before and after intervention. Lastly, we examined the levels of two growth factors, BDNF and IGF-1, before and after the intervention. BDNF was low in both groups before intervention and there was no statistically significant difference between the two groups (Table VII). BDNF levels were significantly higher in both groups after intervention compared to those before the intervention. The levels of BDNF in the experimental group were higher than that in control group after intervention The differences were statistically significant $(\mathrm{p}<0.05)$ (Table VII and Fig. 1). 
Table VI. Renal function after intervention (mean $\pm \mathrm{SD}$ ).

\begin{tabular}{lccc}
\hline Group & Blood urea nitrogen $(\mathrm{mmol} / \mathrm{l})$ & Creatinine $(\mu \mathrm{mol} / \mathrm{l})$ & Uric acid $(\mathrm{mmol} / \mathrm{l})$ \\
\hline Normal & $3.2-6.1$ & $88.4-159.1$ & $89-417$ \\
Experimental & $7.83 \pm 0.35$ & $215.63 \pm 35.13$ & $9.12 \pm 1.0$ \\
Control & $10.31 \pm 2.40$ & $359.61 \pm 48.21$ & $11.20 \pm 0.9$ \\
t-value & 6.467 & 15.265 & 9.778 \\
P-value & $<0.05$ & $<0.05$ & $<0.05$ \\
\hline
\end{tabular}

Table VII. BDNF levels before and after intervention $(\mathrm{ng} / \mathrm{ml}$, mean $\pm \mathrm{SD})$.

\begin{tabular}{lcccc}
\hline Group & $\begin{array}{c}\text { Before } \\
\text { intervention }\end{array}$ & $\begin{array}{c}\text { After } \\
\text { intervention }\end{array}$ & t-value & P-value \\
\hline Normal & $6.15-14$ & & & \\
Experimental & $5.1 \pm 0.2$ & $13.31 \pm 1.25$ & 41.018 & 0.000 \\
Control & $5.1 \pm 0.3$ & $8.21 \pm 0.93$ & 20.129 & 0.000 \\
t-value & 0.000 & 20.703 & - & - \\
P-value & 1.000 & $<0.05$ & - & - \\
\hline
\end{tabular}

BDNF, brain derived neurotrophic factor.

Table VIII. IGF-1 levels before and after intervention ( $\mathrm{ng} / \mathrm{ml}$, mean $\pm \mathrm{SD})$.

\begin{tabular}{lcccc}
\hline Group & $\begin{array}{c}\text { Before } \\
\text { intervention }\end{array}$ & $\begin{array}{c}\text { After } \\
\text { intervention }\end{array}$ & t-value & P-value \\
\hline Experimental & $93.1 \pm 3.3$ & $342.6 \pm 12.5$ & 122.056 & 0.000 \\
Control & $93.2 \pm 3.2$ & $211.2 \pm 10.6$ & 67.401 & 0.000 \\
t-value & 0.138 & 50.707 & - & - \\
P-value & 0.891 & $<0.05$ & - & - \\
\hline
\end{tabular}

IGF-1, insulin-like growth factor-1.

Similarly, IGF-1 was low in both groups before intervention and there was the differences were not statistically significant ( $p>0.05)$ in the IGF-1 level between the two groups before the intervention (Table VIII). IGF-1 levels were significantly elevated in both groups after the intervention than those before intervention. The differences were statistically significant $(\mathrm{p}<0.05)$ (Table VIII and Fig. 2).

\section{Discussion}

Diabetic nephropathy is one of the most common systemic complications in diabetic patients. This problem is caused mainly by glomerular sclerosis due to long-term chronic hyperglycemia (8). The pathogenesis of diabetic nephropathy is complex and most scholars believe that it is mainly caused by renal hypertrophy, thickening of the tubular and glomerular basement membrane due to glomerular hyperperfusion, and increased filtration rate (9). If patients with diabetic

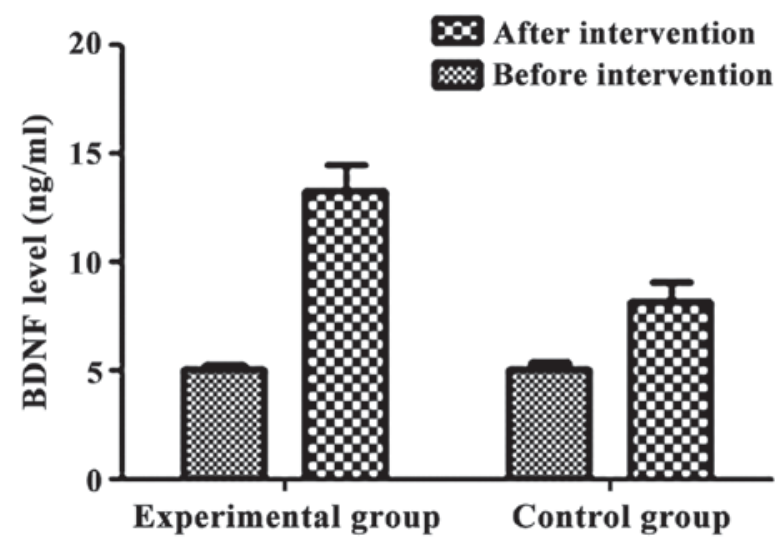

Figure 1. Brain derived neurotrophic factor (BDNF) levels before and after intervention. There was no statistically difference in the level of BDNF between the two groups before the intervention $(\mathrm{p}>0.05)$. After intervention, the levels of BDNF were significantly higher in both groups than those before intervention $(\mathrm{p}<0.05)$. After intervention, BDNF level was higher in the experimental group than that in control group $(\mathrm{p}<0.05)$.

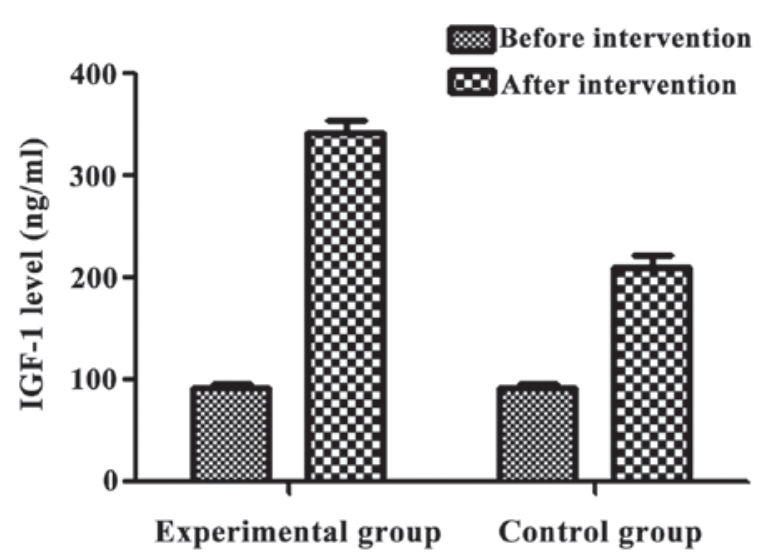

Figure 2. Insulin-like growth factor-1 (IGF-1) levels before and after intervention. There was no significant difference in the level of IGF-1 between the two groups before the intervention ( $\mathrm{p}>0.05$ ). After intervention, the levels of IGF-1 were significantly higher in both groups after intervention than those before intervention $(\mathrm{p}<0.05)$. After intervention, IGF-1 level was higher in the experimental group than that in control group $(\mathrm{p}<0.05)$.

nephropathy are not treated timely, they develop renal failure and even uremia, threatening their lives. Therefore, special clinical attention should be paid to patients with diabetic nephropathy (10).

In this study, patients with diabetic nephropathy received alprostadil alone or alprostadil combined with calcium dobesilate as symptomatic treatment. The remission time of clinical 
symptoms, such as mental fatigue and weakness, limb edema, soreness and swelling of waist and knee, cold limbs and limb numbness and pain, was significantly shorter in the experimental group than that in the control group, suggesting that the combined treatment can more efficiently relieve the clinical symptoms. In addition, the levels of $\beta 2-\mathrm{MG}, \mathrm{CysC}$ and RBP in serum were significantly lower in the experimental group than those in the control group, suggesting that the application of the combined treatment significance improves the renal filtering of small proteins. Moreover, the levels of TNF- $\alpha$, IL-6, CRP and angiotensin II were significantly lower in the experimental group than those in control group. In contrast, the levels of 25-hydroxyvitamin D and parathyroid hormone were significantly higher in the experimental group than those in the control group. Thus, application of alprostadil combined with calcium dobesilate alleviates the inflammatory response and improves the levels of endocrine hormones. Additionally, FINS was significantly higher and HOMA-IR index was lower in experimental group than that in control group. Finally, the levels of BDNF and IGF-1 were higher in the experimental group than those in the control group after intervention, suggesting that the combined treatment increases insulin level, reduce insulin resistance, and regulate the levels of BDNF and IGF-1.

The application of alprostadil combined with calcium dobesilate in patients with diabetic nephropathy can more efficiently reduce the microvascular wall permeability, decrease the whole blood viscosity, and inhibit the platelet aggregation (11-13). These effects significantly alleviate the clinical symptoms, reducing small molecule proteins from blood, and improving renal functions (14). Moreover, calcium dobesilate can also reduce the vascular endothelial injury and inhibit apoptosis, restoring the filtration of small proteins, such as $\beta 2-\mathrm{MG}, \mathrm{CysC}$ and RBP. In addition, calcium dobesilate eliminates oxygen (hydroxyl) radicals and inhibits the inflammatory response (15), reducing the levels of inflammatory cytokines. Moreover, calcium dobesilate can effectively stabilize capillary endothelial cells, reduce endothelial cell rupture (16), improve lymphatic return and other functions (17), inhibit secretion and synthesis of aldose reductase (18), and decrease the levels of sorbitol $(19,20)$, effectively regulating the levels of BDNF and IGF-1.

In conclusion, treatment with alprostadil and calcium dobesilate in patients with diabetic nephropathy effectively relieves clinical symptoms, improves the renal functions, reduces the levels of small molecule proteins in blood, alleviates the inflammatory response, and regulates the levels of BDNF and IGF-1.

\section{References}

1. Hung CC, Lin HY, Hwang DY, Kuo IC, Chiu YW, Lim LM, Hwang SJ and Chen HC: Diabetic retinopathy and clinical parameters favoring the presence of diabetic nephropathy could predict renal outcome in patients with diabetic kidney disease. Sci Rep 7: 1236, 2017

2. Das F, Ghosh-Choudhury N, Venkatesan B, Kasinath BS and Ghosh Choudhury G: PDGF receptor- $\beta$ uses Akt/mTORC1 signaling node to promote high glucose-induced renal proximal tubular cell collagen I $(\alpha 2)$ expression. Am J Physiol Renal Physiol 313: F291-F307, 2017.
3. Chen YL, Qiao YC, Xu Y, Ling W, Pan YH, Huang YC, Geng LJ, Zhao HL and Zhang XX: Serum TNF- $\alpha$ concentrations in type 2 diabetes mellitus patients and diabetic nephropathy patients: A systematic review and meta-analysis. Immunol Lett 186: 52-58, 2017.

4. Eissa S, Matboli M and Bekhet MM: Clinical verification of a novel urinary microRNA panal: $133 \mathrm{~b},-342$ and -30 as biomarkers for diabetic nephropathy identified by bioinformatics analysis. Biomed Pharmacother 83: 92-99, 2016.

5. Gnudi L, Coward RJ and Long DA: Diabetic nephropathy: Perspective on novel molecular mechanisms. Trends Endocrinol Metab 27: 820-830, 2016.

6. John S: Complication in diabetic nephropathy. Diabetes Metab Syndr 10: 247-249, 2016.

7. Yun KJ, Kim HJ, Kim MK, Kwon HS, Baek KH, Roh YJ and Song KH: Risk factors for the development and progression of diabetic kidney disease in patients with type 2 diabetes mellitus and advanced diabetic retinopathy. Diabetes Metab J 40: 473-481, 2016.

8. Kubota M, Watanabe R, Yamaguchi M, Hosojima M, Saito A, Fujii M, Fujimura S and Kadowaki M: Rice endosperm protein slows progression of fatty liver and diabetic nephropathy in Zucker diabetic fatty rats. Br J Nutr 116: 1326-1335, 2016.

9. Al-Rasheed NM, Al-Rasheed NM, Al-Amin MA, Hasan IH, Al-Ajmi HN, Mohammad RA and Attia HA: Fenofibrate attenuates diabetic nephropathy in experimental diabetic rat's model via suppression of augmented TGF- $\beta 1 / \mathrm{Smad} 3$ signaling pathway. Arch Physiol Biochem 122: 186-194, 2016.

10. Jose MJ, Varkey V, Chandni R, Zubaida PA and Maliekkal J: The role of smoking as a modifiable risk factor in diabetic nephropathy. J Assoc Physicians India 64: 34-38, 2016.

11. Liljedahl L, Pedersen MH, Norlin J, McGuire JN and James P: $\mathrm{N}$-glycosylation proteome enrichment analysis in kidney reveals differences between diabetic mouse models. Clin Proteomics 13: 22-27, 2016.

12. Wang M, Yao D, Wang S, Yan Q and Lu W: Long non-coding RNA ENSMUST00000147869 protects mesangial cells from proliferation and fibrosis induced by diabetic nephropathy. Endocrine 54: 81-92, 2016.

13. Ma R, Chaudhari S and Li W: Canonical transient receptor potential 6 channel: A new target of reactive oxygen species in renal physiology and pathology. Antioxid Redox Signal 25: 732-748, 2016

14. Hanefeld M, Appelt D, Engelmann K, Sandner D, Bornstein SR, Ganz X, Henkel E, Haase R and Birkenfeld AL: Serum and plasma levels of vascular endothelial growth factors in relation to quality of glucose control, biomarkers of inflammation, and diabetic nephropathy. Horm Metab Res 48: 620, 2016.

15. Ge J, Miao JJ, Sun XY and Yu JY: Huangkui capsule, an extract from Abelmoschus manihot (L.) medic, improves diabetic nephropathy via activating peroxisome proliferator-activated receptor (PPAR) $-\alpha / \gamma$ and attenuating endoplasmic reticulum stress in rats. J Ethnopharmacol 189: 238-249, 2016.

16. Kang YS, Lee MH, Song HK, Kim JE, Ghee JY, Cha JJ, Lee JE, Kim HW, Han JY and Cha DR: Chronic administration of visfatin ameliorated diabetic nephropathy in type 2 diabetic mice. Kidney Blood Press Res 41: 311-324, 2016.

17. You YK, Huang XR, Chen HY, Lyu XF, Liu HF and Lan HY: C-reactive protein promotes diabetic kidney disease in $\mathrm{db} / \mathrm{db}$ Mice via the CD32b-Smad3-mTOR signaling Pathway. Sci Rep 6: $26740,2016$.

18. Ji ZZ and Xu YC: Melatonin protects podocytes from angiotensin II-induced injury in an in vitro diabetic nephropathy model. Mol Med Rep 14: 920-926, 2016.

19. Lu Y, Tang L, Li Y and He Q: High glucose-induced fibronectin upregulation in cultured mesangial cells involves caveolin-1dependent RhoA-GTP activation via Src kinase. Mol Med Rep 14: 963-968, 2016.

20. Misra A and Shrivastava U: Obstructive sleep apnea and diabetic nephropathy. Diabetes Technol Ther 18: 405-407, 2016. 